\title{
El camino del santazo. La narrativa del padecimiento misionero en Urabá, Colombia
}

\author{
Aída Gálvez Abadía \\ Antropóloga, profesora de la Universidad de Antioquia, Medellín \\ agalvez@geo.net.co
}

\section{Resumen}

- lartículo aborda los Últimos años del CARMELIta descalzo José Joaquín [ Arteaga de la Virgen del Carmen, quien administró la prefectura apostólica de Urabá (1919-1926), en los actuales departamentos de Antioquia y Chocó (Colombia). Analiza la oscilación del personaje entre el cumplimiento del deber y la exigencia de garantías de salud, menguada por accidentes y dolencias tropicales. Agobiados por el inhóspito U rabá, Arteaga y sus misioneros renuncian en 1921 Se estudian las reacciones suscitadas por el hecho en Colombia, España y el Vaticano y el impacto de estas en la biografía del prefecto. El redescubrimiento de la dimensión existencial de la enfermedad, propio de los recientes estudios, permite elaborar la biografía de padecimiento del misionero, abordado general mente por la disciplina como actor colectivo antes que como individuo.

PalabRas ClaVE: misionero, padeci miento, enfermedad, narrativa, Urabá.

\section{Abstract}

This paper addresses the last seven years of the life of barefoot Carmelte missionary, Jose Joaquin Arteaga, Director of the Apostolic Prefecture of Uraba, a zone between Antioquia and Choco, in Northwestern Colombia, from 1919 to 1926 It examines his constant movement between duty and claims for improved health conditions, already deteriorated by accidents and tropical disease. Overwhelmed by the inhospitable nature of Uraba, Arteaga and his missionaries were forced abandon the mission in 1921 The article examines the various reactions to this abandonment in Colombia, Spain, and the Vatican, as well as their consequences on the prefect's biography. The rediscovery of the existential dimension of illness allows for a detailed approach into the biography of missionary suffering, generally examined by scholars as collective actors rather than as individuals.

KEY wORDS: Missionary, suffering, narrative, illness, Uraba. 


\title{
I NTRODUCCIÓN*
}

\begin{abstract}
5
* Este artículo reelabora un capítulo de la tesis "Por obligación de conciencia. Los misioneros del Carmen Descalzo en Urabá, Colombia. Siglo XX", requisito del doctorado en antropología de la medicina en la Universitat Rovira i Virgili de Tarragona (Es-

Agradezco a la hermana Noemí Pérez, carmelita misionera, a Rafael Mejía, OCD, y a Hernando Uribe, 0 CD, por su apoyo en la realización del trabajo de campo y de archivo en Colombia. A la antropóloga Alba Doris López R. por sus comentarios al artículo.

1. Esta es una estructura supraparroquial bajo el gobierno de un prefecto apostólico nombrado por el Vaticano pero sin la investidura episcopal, aunque en ciertos aspectos se le reconoce facultades de ordinario u obispo en el ejercicio de su jurisdicción (Álvarez, 2001).
\end{abstract} NTRE LOS SIGLOS DIECINUEVE Y VEINTE, LA ESTRATEGIA DE INCORPORAción de las regiones periféricas y de los grupos indígenas a la nación colombiana consideraba al catolicismo como principal ingrediente civilizador. Por ello, desde 1893hasta 1949 se implantaron en el país catorce jurisdicciones misionales, la mitad erigidas entre 1910 y 1920, siendo otorgada una cuarta parte de éstas a comunidades religiosas españolas (Córdoba, 2001: 164 y ss.). El territorio comprendido entre las bandas oriental y occidental del golfo de Urabá y que remonta en dirección este las estribaciones selváticas de la cordillera andina fue autorizado paña), 2003 por el gobierno colombiano a la orden española del Carmen Descalzo en la modalidad de prefectura apostólica ${ }^{1}$, para impartir asistencia religiosa a las etnias embera y kuna y a la población general de la región entre 1918 y 1941 En desempeño de la acción apostólica, los carmelitas descalzos movilizaron sus "capitales de abnegación y heroísmo" en la selva de Urabá. Este artículo analiza cómo el sufrimiento justifica la acción misionera por la sal vación de las almas, historia que elegí contar tomando la voz de Joséjoaquín de la Virgen del Carmen, primer prefecto apostólico. De entrada advierto que no me propuse la biografía del prefecto, sino, únicamente, la comprensión de los años finales de su vida (1919 a 1926), coincidentes con la labor misional en Urabá.

Tradicional mente, la antropología se ha inclinado a comprender la constitución y funcionamiento de los sistemas culturales más que hacia el análisis de las trayectorias individual es (Pujadas, 1992); el método biográfico dominante en este artículo Ileva al punto de convergencia entre: " 1 el testimonio subjetivo de un individuo a la luz de su trayectoria vital, de sus experiencias, de su visión particular, y 2. Ia plasmación de una vida que es el reflejo de una época, de unas normas sociales y de unos 
val ores esencial mente compartidos con la comuni dad de la que el sujeto forma parte" (Ibid.: 44). Mientras los investigadores social es escogen ante todo personajes margi nal es para abordarlos desde dicho método, preferí trabajar el personaje de un misionero, sujeto incómodo en la literatura antropológica, bajo la presunción de que vidas como la del prefecto Arteaga comunican las contingencias que también acechan a quienes ocupan posiciones en el eje del poder, la misma que ha motivado la reticencia de los antropólogos a la hora de definir los protagonistas de los estudios.

Me aproximé desde 1999 a la obra del carmel ita Severino de Santa Teresa -sucesor del prefecto Arteaga en la administración de la prefectura apostólica-, notando que los días de los frailes se escribían en clave de sufrimiento. Parece que fray Severino buscara anteponer al lector las penurias de los padres en las correrías por "ese encenagado rincón del trópico" que era para ell os Urabá. Pági nas enteras describen una naturaleza avasalladora, que somete a los misioneros por la enfermedad, el accidente y la incertidumbre 2 . Decidí pues sondear en la bibliografía carmelitana la experiencia del padecimiento, su lugar dentro de la visión religiosa del mundo y la manera como se articuló en las modernas misiones de comienzos del siglo veinte. La investigación se enriqueció con el acceso a los archivos de la orden carmelita en España, Italia y, en menor medida, en Colombia, y dentro de estos, a los "documentos personales" o conjunto de registros escritos alusivos a una trayectoria humana, que transmiten la visión subjetiva de los sujetos tanto de la real idad que los circunda como de su propia existencia (Pujadas, 1992) y que sin haber sido solicitadas por el investigador son producto de la iniciativa personal, del deseo por fijar la experiencia cotidiana, legitimar una existencia y presentar un legado para la posteridad ${ }^{3}$.

2. Sobre el "tributo de sangre" pagado en los siglos dieciséis-diecisiete por las misiones agustinas recoletas, franciscanas, capuchinas, jesuitas y dominicas durante el Patronato español en la Nueva G ranada, y genéricamente referidas al área estudiada, véase Santos, 1978: 246-249. La apología del desempeño misionero en el medio tropical es un componente estructural de la literatura misionera hasta la actualidad; en el ámbito carmelitano véase, por ejemplo, Rodríguez (1995). Sobre la saga del misionero javeriano Carlos Alberto Calderón, muerto por malaria en Kenia en 1996, véase Fernández (2001).

3 Para las condiciones de surgimiento del género autobiográfico a principios del siglo diecinueve, al cual se asocian los diarios personales y el epistolario, véase Weintraub (1991). La toma de conciencia sobre la originalidad de cada vida es un producto cultural tardío de la civilización occidental. Véase G usdorf, 1991 9-11 


\section{Perspectiva conceptual}

OS SISTEMAS RELIGIOSOS EN GENERAL HAN INTEGRADO EL SUFRIMIENTO humano en su explicación del universo; la teodicea trata de responder a la paradoja de por qué las divinidades de calificación positiva coexisten con mundos imperfectos, donde ocurren desgracias, enfermedades y la muertet. En la historia de las ideas religiosas el padecimiento surgió como un signo de

4. En el catolicismo se encara el problema de la teodicea transfiriendo de modo masoquista la cuestión de la justicia divina a la de la condición pecadora del hombre. Según Berger, se troca la teodicea en una cuestión de antropodicea. La doctrina cristológica define la relación entre el Dios que castiga y el Dios que sufre. El Dios encarnado es uno profundamente vulnerado y mediante su sufrimiento y agonía en la cruz, la Encarnación gana en potencialidad religiosa (Berger, 1971). Así, un Cristo sufriente por voluntad propia despoja al sufrimiento de su carácter injusto e incide en que las penalidades sean vistas como necesarias ( $C$ amus, citado en Berger, 1971: 116). antipatía de los dioses, las dolencias de los sufrientes se traducían como una culpa secreta, y por ello eran marginados de los rituales. Paulatinamente se cambió el estatus negativo del sufrimiento hasta consolidarse como una vía para alcanzar estados extraordinarios (Weber, 1978: 12). La consideración sobre el carácter de los val ores sagrados promovidos por las diversas religiones es indispensable para comprender la biografía individual. Acorde con Weber, tales valores fueron original mente "bienes de este mundo" cal ificados posi tivamente: salud, Iarga vida y riqueza. El cristianismo y otros credos ascéticos se exceptúan de este tipo de promesas, privilegiando valores sagrados extraterrenos. La disposi ción hacia dichos val ores no desvirtuó el esfuerzo humano por constatar el estado de gracia permanente, basado en el sentimiento de prueba de sí mismo, que concreta los val ores en religi ones de ascesis (Ibid.: 21).

Hasta el medioevo, la aceptación del dolor fue una forma de acercami ento a Dios, una oportunidad de participar en el sufrimiento de Jesús en la cruz. El catolicismo desarrolla una forma de culto al dolor como método de aproximación a Dios, para devenir en una búsqueda voluntaria, prueba de la excepcionalidad emparentada con la santidad. Ya no será indicio de falta ante la divinidad, sino oportunidad de salvación, para sí mismo y para otros (Le Breton, 1999).

El estilo de vida religioso real za el padecimiento, magnificado en la fisonomía del misionero, como persona que al ejada de su patria y de su medio natural propaga la religión católica por 
cual quiera de los medios de apostolado quela iglesia admite (Rodríguez, 1955). Se llega a la vocación mi sionera con la certeza de quela misión es el máximo ideal de vida cristiana, tarea que vinculaal misionero di rectamente con la pureza de los primeros cristianos (Álvarez, 1998); tal vocación implica la búsqueda de las peores condiciones, ya que “...siendo esta empresa del agrado de Dios, no le había de faltar la protección de lo al to"5:

\begin{abstract}
[...] son extraordinarios porque dejaron todo y llegaron a estos lugares con un ideal el evadísimo, excelso, el de ganar al mas, cerrando los oídos a los reclamos de la naturaleza que exige lo suyo, que instintivamente rechaza todo lo que es pesado, que aborrece el sufrimiento y el dolor, que preferiría una vida más cómoda, más hol gada, más excenta (sic) de sacrificios y privaciones; por eso son extraordinarios, y son locos con la locura de la Cruz, porque saben que bajo esos cuerpos toscos e inexpresivas miradas se encuentran unas almas por las que Cristo derramó hasta la última gota de su sangre en el Calvario y su caridad les urge, les fuerza a darles la mano para queno perezcan eternamente. ¡Sublime locura que siendo insensatez a los ojos del mundo, les acarreará un puesto de gloria en el cielo! (Bernardino del Niño Jesús, 1945 21)
\end{abstract}

Una de las concepciones de la personal idad configurada en el medioevo cristiano corresponde a la Imitatio Christi. Como todo modelo, condensa val ores y convicciones con un contenido concreto: "exigen unas cualidades determinadas, instan a este o a aquel conjunto de valores, recomiendan encarecidamente modos de vida específicos y prescriben normas y conductas" (Wientraub, 1991: 27) ${ }^{6}$. El grupo de misioneros formados en el modelo de imi tación de Cristo se ajustó durante su permanencia en Urabá al ideal normativo de "héroes" o "soldados del Evangelio". Dada la imposibilidad de replicar no sólo éste sino cualquier otro model o en las vidas concretas, y por el hecho de que los modelos no prescriben la totalidad de la experiencia humana, el tono dominanteen la narrativa del padre Arteaga y de otros frailes abordados tangencialmente oscila entre la apelación al modelo cristiano y las

5 Circular del provincial de la provincia agustina recoleta de $\mathrm{S}$. Nicolás de Tolentino a los misioneros de América, 1898, citada en Alonso y Martínez, 1948. En Álvarez, 1998: 200.

6. El texto popularizó las ideas de la corriente espiritual de la Devotio moderna, surgida en los Países Bajos y expandida en Europa entre los siglos quince-dieciséis ( $\mathrm{F}$. Montes de $\mathrm{O} \mathrm{ca}$, "Introducción", en De Kempis, 1999). La imitación de Cristo es la vía de la renuncia que lleva a C risto: "Tota vita Christi crux et martyrium fuit" (Santidrián, 1995 459). Hernando Uribe, OCD, aportó sus comentarios esclarecedores sobre la injerencia del texto en la formación de los frailes carmelitas. 
"variaciones idiosincrásicas" del personaje. El análisis dela narrativa del prefecto Arteaga descubre a al guien que trasciende sus padecimientos hasta corroborar su autenticidad como sufriente en las coordenadas de realidad definidas por la orden

7. Las glosas de Berger al continuum tipológico de las teodiceas sitúan en un extremo la identidad del individuo fundida en la identidad de la colectividad, que puede revestir o no carácter masoquista -en un sentido sartreano y no psicoanalítico-. Esto hace a la persona identificarse con su grupo tanto en la felicidad como en la desgracia. Los hechos de la propia biografía, incluida su muerte, constituyen episodios de la historia general de una colectividad. "C uanto más fuerte sea esta identificación, más débil será la amenaza de anomia proveniente de las desventuras de la biografía individual" (Berger, 1971: 94). religiosa. Acorde con Berger, su sufrimiento y su muerteaparecen como "correctos", atenuándose su carácter anómi co, aunquesin evitar el dolor y la aflicción?.

Este artículo sintoniza con los estudios en antropología y en sociología de la medicina, que recuperan la materia en las últimas décadas del sigl o veinte. Peseaque la experiencia del sufrimiento es connatural a la vida humana, en las representaciones colectivas y en el lenguaje especializado se había reducido el uso del vocabulario moral y religioso del asunto. La visión técnico-racional compartida por la salud pública, la fisiología, la clínica, etcétera, desvirtuó los aspectos morales de esa experiencia, bajo los signos de la modernidad, el desencantamiento y la desmoralización del mundo (Kleinman et al., 1994); el dolor y otras formas de sufrimiento se trivializaron, desconociendo su vigencia en el círculo de la experiencia personal y familiar, y su carácter de experiencia existencial radical y de carga moral.

El rescate de la dimensión existencial de la enfermedad permite actual mente debatir su natural eza, la intervención que ejerce en los procesos de identidad, la dirección de los sentimientos y la emergencia de di lemas existenciales, por resolver en la arena del self o del sí mismo; este concepto alude a una organización de atributos, sentimientos, valores y características que por su carácter evaluativo aporta a la persona una definición de lo que ella es y de los procesos por los que atraviesa ante las crisis de salud y el sufrimiento que conllevan (Charmaz, 1999. 366). El análisis gira en torno a las "narrativas personal es", como recurso de los pacientes que ordena su experiencia, los significados que reviste para ellos y para los demás. La narrativa del padecimiento consiste pues en un relato del paciente, que otros retienen para dar coherencia a lo que ocurre cuando se convive con la enfermedad. Las líneas argumentales, las metáforas y los dispositivos retóricos que estructuran dichas narrativas se basan en 


\section{Revista Colombiana \\ de Antropología

model os cultural es y las hacen significativas para el sufriente y sus próximos (Kleinman, 1988). En la perspectiva fenomenológica de Charmaz, el narrador formula reclamos de identidad como persona y reclamos de realidad ante la(s) audiencia(s) que lo rodea(n), para reforzar su estatus moral, y a la vez que socializa su aflicción reelabora la experiencia de su enfermedad. La autora, a quien sigo de cerca, distingue los siguientes aspectos implícitos en los relatos de padecimi ento: 1) las condiciones en que el sufrimiento permea las fronteras del self; 2) la preservación de un núcleo del sí mismo resistente a las crisis; 3) Ios soportes del self que limitan o detienen la expansión del sufrimiento; y 4) el lugar del self en los relatos del padecimiento y la decisión moral de incorporarlos como parte de la identidad personal (Charmaz, 1999. 367). Se verá cómo lo anterior cohesiona los relatos de padecimiento de Arteaga, en fusión con la marcha de la prefectura apostólica en el Urabá antioqueño. Ahora bien, no se trata sólo de informar sobre las dolencias a determinada audiencia, además de esto, quien socializa sus relatos obtiene "beneficios secundarios", es decir, ventajas personales a partir de los síntomas. Ocurre así un proceso retórico por el cual la queja interviene en el balance de poder que redefine relaciones en el ámbito familiar y laboral (Brodwin, 1994).

Cabe preguntarse entonces el por qué de una narrativa del padecimiento, constitutiva de la experiencia y de la propaganda misionera. La variante fenomenológica del construccionismo plantea que la realidad subjetiva se mantiene mientras se comparta y amplifique con otros. Y es precisamente mediante el lenguaje como el individuo sigue "dándole la réplica" al mundo que lo formó, logrando que el mundo social mente construido funcione como ordenación de la experiencia (Berger, 1971: 37). La queja propia de la escritura misional implicó un uso social, tan eficaz en ciertos col ectivos social es como inoperante en otros. Si convenimos con Berger en que la religión ha sido un agente legitimador de primer orden, por su capacidad de relacionar las precarias construcciones de la realidad de las sociedades empíricas con la realidad última, sobraría el interrogante en torno a una misión urgi da de legi timidad mediante la socialización de sus penalidades. Conviene aquí tener presente que el arribo de los carmel itas descal zos a Antioquia despertó tensiones, especial mente con el clero regional, que exigió a los extranjeros una gestión permanente, siendo la queja parte 
de los recursos desplegados. Adicional mente, a diferencia del antiguo régimen, las modernas misiones religiosas precisaban de la generosidad cristianå.

En la mayor parte de las Misiones sujetas a la Propaganda Fide se carece de carreteras, vías férreas y demás medios rápidos de locomoción. De nuestra Misión de Urabá podemos afirmar que este inconveniente es uno de los mayores y más dispendiosos, que no pocas veces debilita la acción del misionero. No tenemos carreteras ni ferrocarriles; el mar y los ríos son nuestros caminos [... ]. Las costas demar denuestra Prefectura pasan dedoscientas millas [... ] Echarse al mar Caribe en una embarcación de vela es una temeridad imperdonable [...]. No hace mucho que dos Padres de la Misión tardaron ocho días en recorrer treinta millas. Si se levanta alguna tempestad, amenaza un naufragio [... ]. Conseguir un Misi onero cuesta un triunfo; conseguir una lancha misionera tiene que costar un sacrificio. ¿Cómo podrá disponer una misión de 15000 pesetas, que es lo mínimo que puede costar una lancha de las condiciones que en Urabá se necesitan? ¿Qué hacer? [...]. Una limosna, caro lector, y cuenta desde ahora con la gratitud y oraciones de los Misioneros de Urabá (Misioneros de Urabá. "Los misioneros carmelitanos de la misión de Urabá (Colombia)". Revista Carmelitana. Año 8(86). Abril 1931: 100 (Negrilla en el original).

La retórica del padecimiento se comportó así como una poderosa "moneda de cambio", que pudo favorecer los donativos extranjeros, reforzó la imagen de la prefectura ante la sociedad

8. La iniciativa del "Céntimo para la propagación de la fe" aparece ligada a las corporaciones piadosas del siglo diecinueve para apoyar con fondos la causa de las misiones de ultramar. Antes de la primera guerra mundial, hubo en Europa occidental doscientas setenta asociaciones que favorecían el apostolado en países lejanos (Arens, 1922 y 1925 citado en G adille y Zorn 1995 156-58)

9. Véase, Pablo del Santísimo Sacramento, 1944: $188-189$. civil y el gobierno y buscó neutralizar la oposición de algunos prelados antioqueños. Empero, detuvo su circulación a las puertas de quienes justificaban las penalidades misioneras. Merefiero a "las gentes bárbaras", indios y negros, ajenos al círculo donde sufrir es el leit motiv de la existencia. Los infortunios de los frai-

les carecen de resonancia entre aquellos, siempre indiferentes según las fuentes ${ }^{9}$. 


\section{URABÁ, ¿REGIÓN DE MUERTE?}

A PRINCIPIOS DEL SIGLO VEINTE, LA FRONTERA DE URABÁ ERA ASUMIDA por los antioqueños en inferioridad moral. Si los pobladores eran "bárbaros" el correspondiente hábitat era una selva densa y peligrosa, bordeada por un mar embravecido ${ }^{10}$. El determinismo geográfico que prefiguraba la violencia del trópico influenció el discurso médico entre finales los siglos diecinueve y veinte. El riesgo que se corría al viajar a los trópicos dependía de la persona que viajase, de sus condiciones físicas, que garantizarían o no que sobreviviera en esas zonas. En efecto, "un mal de escasa importancia en la vida civil de los climas templados", podía transformarse en "un vicio en las condiciones más exigentes de los trópicos". Desplazarse a tales latitudes resultaba prácticamente una aventura que demandaba una salud excelente, sin deficiencias en el sistema inmunológico que dispo-

10. Urabá encajaba en la antigua imagen del mundo que oponía las regiones extremas y "frías" del orbe al "calor" del viejo mundo, imagen reactivada por el discurso de la llustración. El húmedo continente americano se consideraba producto de los azotes del Diluvio: ríos inmensos, montañas empantanadas, indicios de una desecación imperfecta (Bufón, en G erbi, 1960). ney expone a las enfermedades tropical es (Manson-Bahr, 1924, citado en López y Blair, 2002: 45-46). La localización de las misiones entre ambos trópicos implicaba la permanencia en selvas y climas tropicales y ecuatoriales desde el sur de México hasta la frontera norte de la Argentina, con lo cual la alta temperatura y la humedad constantes representaron un fuerte choque para los frailes, siendo la mayoría natural es del país vasco (Álvarez, 1998: 219). Las mi siones vascas en Hispanoamérica formularon paliativos para proteger al personal del inevitable "tributo" a las endemias tropicales. Se apoyaron en la carta apostólica Maximum Illud, emitida por Benedicto xv, que planteó el principio de "acomodación", útil para lograr el arraigo del personal misionero. Los ajustes versaban sobre la confección de hábitos en materiales livianos, la mitigación de los estrictos horarios de comidas y de rezos, propios del ambiente conventual, y la autorización de reposo en conventos por fuera de la jurisdicción misional (Álvarez, 1998).

Los misioneros dirigidos por el prefecto Arteaga buscaban garantías para su bienestar físico, que ya en el terreno consideraron indispensables para el apostolado. El riesgo de contraer enfermedades tropicales y sobre todo paludismo, definido por 
un médico conocedor de la región como "un formidable morbo que ejerce su labor de muerte entre los moradores del trópico" (Muñoz, 1920) fue un argumento central en la brega entre los misioneros carmelitas y el clero regional, a la defensa de sus respectivos intereses religi osos y jurisdiccionales. La "mansión defieras" de $31.000 \mathrm{~km}^{2}$ que representaba Urabá para los carmel itas, cambiaba en Frontino, un auténtico oasis por las características dela cabecera municipal y por la benignidad del clima.

Los carmel itas descalzos habían Ilegado al país en 1911como orden regular, fundando primero Villa de Leyva (Boyacá) y luego las casas de Frontino y Sonsón (Antioquia). Aunque la propuesta original del convenio de misiones entre Colombia y la Santa Sede (1902) era vincularlos a la misión diocesana para los indígenas de Antioquia, en los años siguientes surgió el proyecto de una jurisdicción ecl esi ástica autónoma, la prefectura apostólica de Urabá (Restrepo, 1979). Mientras tanto, la extensa diócesis de Santa Fe de Antioquia -que regía sesenta y dos parroquias hasta 1915-, dio lugar en ese mi smo año a las diócesis de Jericó y luego a la de Santa Rosa de Osos (1917). Se frustró para los misioneros la obtención de Frontino como capital de la prefectura y residencia del prefecto, ahora imprescindible para la curia de Santa Fe de Anti oquia, limitada en 1917 a seis parroquias (Botero, 1980). Sin Frontino los carmelitas perdían ingresos parroquial es superiores a $\$ 1000$ anual es, una fel igresía que ascendía a diez mil habitantes, vinculados a una actividad agrícola y minera -la Frontino Gold Mines-, además de servicios de correo y telégrafo, difíciles dehallar en otros puebl os dela jurisdicción misional. El Vaticano autorizó el uso de la población a los misioneros sólo como "residencia de salud" y el prefecto debió instalarse en Puerto César, a orillas del golfo de Urabá (véase el mapa).

El contraste de la imagen de Urabá como "región de muerte" se expresa de vez en cuando en el material analizado. Así, un turbeño se dirige a los carmelitas para reconocer que "el clima no es sano", pese a lo cual recomi enda a Turbo como sede de la prefectura por "la abundancia providentísima de la región" (APSJN, caja 4, folder Urabá-Frontino Correspondencia (1a) 19131920. Turbo, 30-I-1916). Un observador de la época opinaba que "la leyenda de insalubridad de Urabá" se repetía con "inconciencia automática" por empleados públ icos deseosos de atribuirse "ejecutorias heroicas". Anota que por ser Urabá una floresta tropical 
MAPA 1

UBICACIÓN DE LA ZONA DE ESTUDIO

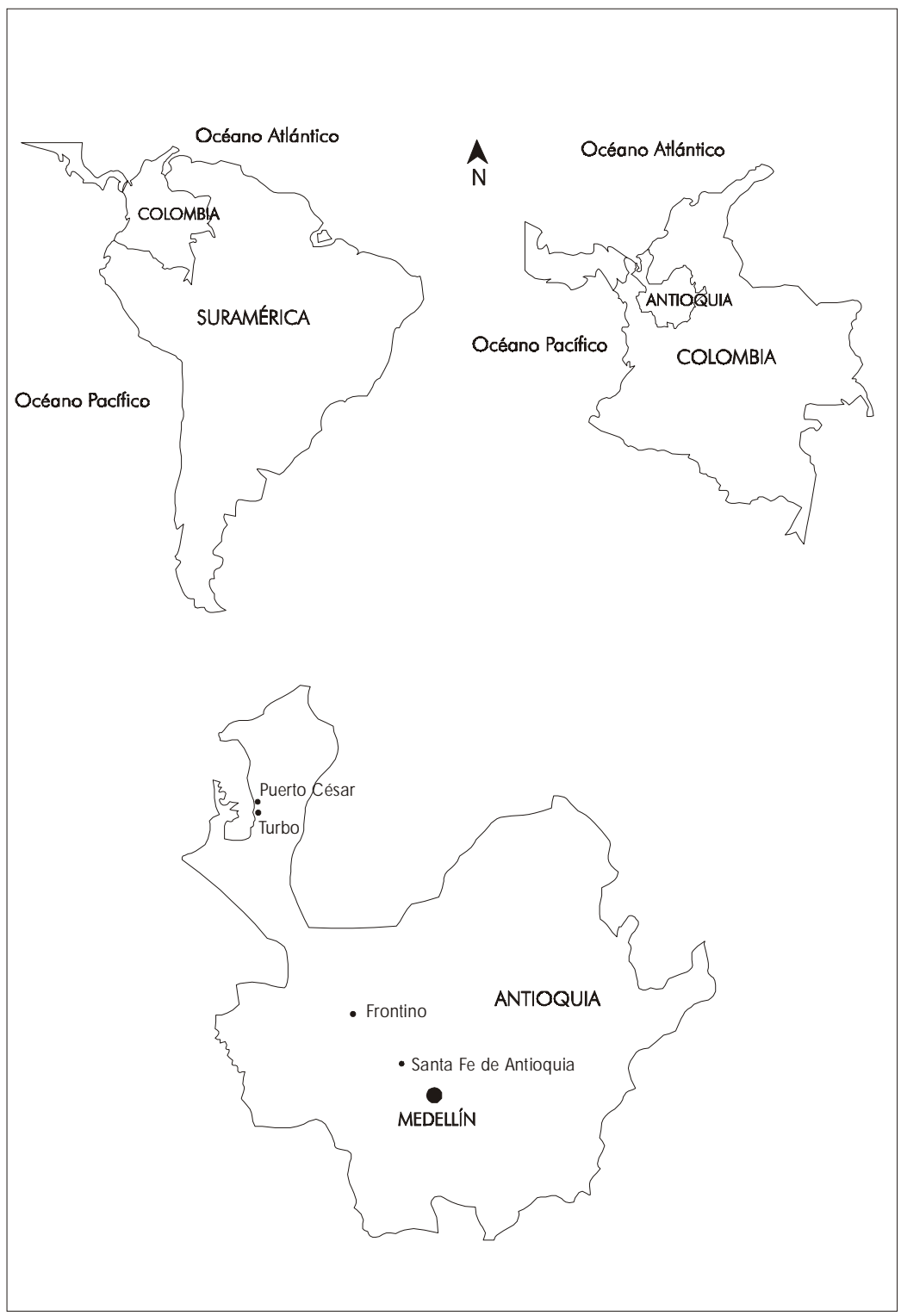

Fuente: G álvez, Aída. "Por obligación de conciencia. Los misioneros del Camen Descalzo en Urabá (Colombia)". Tesis doctoral. Programa de doctorado en antropología de la medicina. Universitat Rovira i Virgili. Tarragona (inédito), p. 29. 
escasamente desmontada abunda el anofeles, pero, al compararla con las hoyas de los ríos Magdal ena y Cauca, resul taba aún peor la infección en esas regi ones. El viento del sur del invierno y las brisas noroeste del verano, son "dos poderosos ventiladores sanitarios" que barren la plaga y tonifican el ai rey, no obstantela carencia de medios curativos y preventivos, los habitantes negros, indios, mulatos y aún los blancos, gozan por lo general de "condiciones normal es de sal ud, apreciablelongevidad, numerosa prole y al egría de vivir" (Villegas, 1954: 90).

\section{SEMBLANZA DEL PERSONAJE}

$\int$ erafín Joaquín Arteaga San Julián, quien al ordenarse tomó el nombre de José Joaquín de la Virgen del Carmen en 1906, fue el egido por los superiores de la orden y por la Sagrada Congregación de Propaganda Fide (SCPF) como primer prefecto apostólico. Nacido en Estela (Navarra) en 1878, fue hijo único de un militar carlista y de una madre que al enviudar ingresó, en 1920, con las debidas dispensas, al monasterio de carmelitas descalzas de Soria (España). Arteaga deci dió su ingreso a la orden para cumplir una promesa hecha a la virgen de El Carmen, que lo salvó de morir durante un baño en la bahía de Santander, mar Cantábrico (Mesa, 1999. 303).

La orden carmelita descalza, como otras órdenes regulares, venía de ser restaurada en 1868 , luego de que las medidas del gobierno liberal de España ocurridas a la muerte de Fernando VII, con sus secuelas de exclaustración y confiscación de bienes religiosos, las habían desestructurado y obligado al exilio entre 183 y 1851 La redefinición de los vínculos entre iglesia y estado auspiciada por el reinado de Alfonso XII favoreció que

11 La orden nació entre un grupo de ermitaños del monte Carmelo en Palestina, inspirados en el profeta Elías del siglo noveno a.C.; a principios del siglo trece, bajo la presión sarracena, emigraron hacia occidente; a fines de ese siglo se integraron a las órdenes mendicantes; Teresa de Jesús es la gran reformadora del Carmelo, en el ambiente tridentino del siglo dieciséis. La reforma carmelita se dividió en el diecisiete en dos congregaciones independientes, la española de san J osé y la italiana de san Elías, aunque $\sigma$
Hispanoamérica se considerara "el área natural de expansión" para las órdenes misioneras. La trayectoria dela orden, cuya densi dad histórica es imposi ble abordar aquí, ha estado marcada por la tensión entre la vida contemplativa y la vida de apostolado exterior en tierras de misión ${ }^{11}$. El 
tiempo histórico que cubrió la vida de fray Arteaga correspondió, como nunca antes en el devenir carmelitano, a la expansión de las misiones vascas y españolas en Hispanoamérica.

Cuando fue designado prefecto, el 15de abril de 1919, el padre Arteaga era prior del convento de Burgos, luego de haber sido profesor y director del colegio de Villafranca de Navarra. La posición que ocupaba poco o nada tenía que ver con su destinación en las Américas: "A tiempo que el orador carmelita disfrutaba en Burgos de autoridad y prestigio, sorprendióle el nombramiento para prefecto apostólico de Urabá. ¡Duro cambio! Dejar la ciudad de Burgos, cabeza de Castilla, por la selva inhospitalaria de Urabá" (Mesa, 1999: 303). Cumpliendo con el voto carmelita por el cual "si la Obediencia lo mandare" debería marchar a tierras de mi sión sea cual fuere su estatus, Arteaga acomodó sus dotes de liderazgo a una intensa labor evangelizadora y de cooperación con el gobierno antioqueño, hasta lograr en poco ti empo que la prefectura apostól ica se convirtiese, en palabras de Álvarez, en "un órgano político cuasidepartamental" (Álvarez, 1998: 131).

Un bosquejo del lugar dela salud corporal en la orden carmelita indica que la fortaleza física de los aspirantes era requisito de la elección: “Los que vayan a desempeñar la del egación apostólica por Cristo entre infieles de naciones extranjeras, deben brillar por tal santidad de vida y cel o por las al mas, quesin ellos decirlo, se vea la pureza y la divinidad y gozar de tal es dotes de alma y cuerpo, que puedan en todo momento dar testimonio de su fe" (Instructiones Missionum Ordinis Carmelitanum Discalceatorum, 19133 Original en latín). Empero, en Ios colegi os donde se formaban los novicios dominaban la austeridad, la baja disponibilidad de alimentos y la carencia de cal efacción que mitigara los rigurosos inviernos del norte de España. La tuberculosis era común en los conventos y las epidemias de gripe, como la que asoló al país vasco en 1918, cobraron vidas entre los colegial es ${ }^{12}$. El convento deVilla de Leyva, por su clima seco, resultó apto para la recuperación de jóvenes carmelitas

seguían formando una única orden carmelitano teresiana. La rama italiana consolidó la vocación misionera, mientras, en general, la española suscribió la orientación de retiro y clausura. La congregación española se suprimió en 1875y durante la fusión se adoptaron las Constituciones de la italiana. Para la historia de la orden, véase Moriones 1978y 1997. Sobre la tensión entre la contemplación y la acción dentro de un estilo propio del misionero carmelitano teresiano, véase Fernández de Mendiola (en prensa).

12. APSJN, Memoria de religiosos que han fallecido en este convento de Marquina desde el año de 1872; también los Libros de Difuntos conservados en los conventos de la provincia. 
de la provincia de San Joaquín de Navarra. Algunos de estos, como el propio fray Severino, quien a mediados de los años veinte presentaba "un amago de tisis", o Remigio del Niño Jesús, afectado por tuberculosis, permanecieron inicialmente en Villa de Leyva, antes de llegar a Urabá.

\section{LLEGADA A FRONTINO}

L AMBIENTE PRESAGIABA GRANDES DIFICULTADES PARA LA EJECUCIÓN del proyecto misional, como lo percibía un fraileque lo antecedió en la comarca:

Hace tiempos que hablamos por aquí de la Prefectura, nos parece un sueño al gunas veces y otras real idad. ¡Qué cruz más pesada prepara Dios nuestro Señor al pobrePadrePrefecto, si ello sehace! y quésantazo se puedehacer si sabe aprovecharse de los trabajos que levengan, que por lo que barrunto, no serán escasos! Pero si Dios lo quiere, todo saldrá bien (APSJN, Jerarquía carmelitana, Superior provincial, correspondencia 1900-1921, carta de Elías del Santísimo Sacramento a Ezequiel del Sagrado Corazón de Jesús, Frontino, 14-IV-1919).

La intuición del fraile se cumpliría a cabalidad: si bien la prefectura dirigi da por el padre Arteaga despegó a partir de la década de 1920, logrando en un corto lapso abundantes real izaciones materiales y espiritual es ${ }^{13}$, Ios "trabajos" que ello supuso, comprometieron severamente la vida del prefecto, hasta su muerte en 1926.

Dos semanas después de su llegada a Frontino, el padre Arteaga realizó la primera excursión apostólica, en la que contrajo fiebres su acompañante, fray Amando de la Virgen del Carmen. Una vez penetra en los distritos montañoso y marítimo de la prefectura, confirma la importancia estratégi ca de Frontino para la acción misional. El optimismo y el vigor que lo acompañaban

B El mayor esfuerzo de los carmelitas en la implantación de fundaciones de la prefectura se desarrolló durante la década de 1920, cuando se establecieron doce de las dieciséis fundaciones realizadas durante la vigencia de esta jurisdicción misional (Córdoba, 2001: 230). a su arribo a la población, cuando confiaba en el buen curso de las iniciativas quetenía en mente (APSJN, Urabá, correspondencia (1a) 1913 1920, cartas de Arteaga al Provincial, Frontino, 29-1x-1919 y 1XI1919), ceden ante la aflicción y la 
enfermedad. A los pocos años de permanecer en Urabá, la experiencia del prefecto se parangonó con "un huerto de Getsemaní": "iVerse él, con sus dotes espléndidas, con el lujo de su personalidad, su poderoso cúmul o de energías espirituales, aislado, perdido en la soledad estéril de esa comarca incomunicable y malsana!" (Mesa, 1999. 303).

La incursión en el territorio misional despertó inquietud en Arteaga y en sus subordinados frente a la obediencia debida a los superiores. La actitud controversial informa sobre lo insoportable que debió resultarles Urabá, máximesi recordamos que el sufrimiento se normalizaba en la mentalidad religiosa, desde la identificación con el Cristo sufriente ${ }^{14}$. El sentimiento de falta de confianza patente en la narrativa misional se refería a los medios humanos que rodeaban a los misioneros ya que "la de Dios no nos falta" (APSJN, Urabá, correspondencia (2a) 1921-1925, carta de José Joaquín Arteaga a Provincial, Frontino, 14-XII-1921).

14. Las Instrucciones de Formación de los N ovicios ilustran al respecto: "[... ] Causa, en verdad, admiracion el ver la gran serenidad de espiritu y de semblante con que sufren los dolores, dando continuamente gracias á Jesucristo por haberse dignado hacerles participantes de sus padecimientos. De aquí que jamás se les oiga quejar de nada; ni buscan el más mínimo consuelo ó alivio para sus enfermedades; antes, por el contrario, los que les son ofrecidos, los rehusan con disimulo; ni aflojan en la observancia, ni en las mortificaciones en cuanto lo permite la enfermedad y la anuencia de la santa 0 bediencia. ¡Tanto puede en ellos el ódio verdadero que tienen de sí y el amor á Cristo crucificado!" (Ildelfonso de Santo Domingo, 1879. 221).

\section{LA FIEBRE, INSEPARABLE COMPAÑERA}

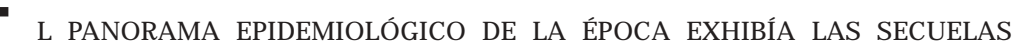

- de la guerra de los mil días (1899-1902), que pauperizó al país - y generalizó las enfermedades infecciosas respiratorias e intestinales, la malaria y la fiebre tifoidea, entre otras. La marginalidad de Urabá se expresaba en la ausencia de recursos de salud: "Cuando uno cae enfermo en la prefectura, si está en el golfo, debe irse a Cartagena; y si es en estas parroquias de Urama o Dabeiba, subirse cuanto antes a Frontino; porque en toda la Prefectura ni hay botica ni médicos", escribe uno de los frailes desde el sanatorio de Frontino, reponiéndose de dolencias del estómago por "Ios cal ores de Dabeiba" (APSJN, Jerarquía carmelitana, Superior provincial, correspondencia 1921-1926, carta de Pascual de Santa Teresa a Ezequiel del Sagrado Corazón de Jesús, Frontino, 25॥II-1926). 
En caso de urgencia, los misioneros eran socorridos por curanderos de la región, sin que haya referencias a tratamientos de los frailes con curanderos embera y kuna. Mientras permanecieron en la base misional del golfo, los frailes accedían a algunos médicos que atendían a la población:

El Dr vino con objeto de ver a José Muñoz uno de los sirvientes el cual encontró muy débil. Compuso para él una toma compuesta de onza y media de sal glauber, gramo y medio de quinina y el jugo de un limón, todo disuelto en un vaso de agua, y tomarlo de una vez. Recomendó mucho esto cuando se trataba de un paludismo agudo cómo (sic) el de José, y que, cuando se tratara de un paludismo crónico se tomaba en tres partes con el intervalo de una hora (A nónimo, Diario de El Carmelo 1921-1923 20-21 Subrayados míos).

Las "fiebres" Inicialmente despiertan temor, como sucede con uno de ellos que pasa sus primeros días en Murindó:

Acabo de recibir un aviso de que el Padre Alberto se halla grave en Murindó e inmediatamente he despachado un padre con medicinas, pero no llegará al lá sino al tercer día. El despacho dice así: "Padre Alberto grave, complicación, fuerte fiebre, vómito. Ruégole envían médico, formular telegráficamente". De aquel pueblo al primero que tienetel egrafía hay dos días de camino. Creemos queseráa a gún acceso fuerte de fiebre y como es la primera vez que le da, se ha asustado mucho (APSJN, Jerarquía carmelitana, Superior provincial, correspondencia 1926-1933, carta de Severino a P. Ezequiel, Turbo, 9.IV1934. Subrayado mío).

Los misioneros aprenden a soportarlas y a sacar partido de los lapsos en que desciende su intensidad, aprovechados para continuar las tareas durante las correrías apostólicas. La falta de vigilancia epidemiológica en la región al entó lo que para el los resultaba ser la cronicidad de la sintomatología malárica y dio paso a una habituación que admiró a otros carmelitas español es que recorrieron Urabá. Como "efecto necesario de la visita" cae enfermo uno de ellos: "Todavía recuerdo cómo se reía de mí el buen P. Severino, al verme impresionado con aqueIla fiebre para mí desconocida, como se ríe el sol dado veterano del pobre bisoño, sin experiencia de la vida militar" (APSJN, Biográficas 5 Borrador de las palabras pronunciadas por el P. Amalio de San Luis Gonzaga en el acto de celebración familiar de 
quincuagésimo aniversario de profesión religiosa de Severino de Santa Teresa, s.f.: 꾤).

La experiencia con los estados febriles sobresale en las narrativas de padecimiento de los frailes, por la marca que ejerce durante su permanencia en territorio misional. Si bien la epi demi ol ogía de la mal aria nos enseña actual mente que esta no es una enfermedad crónica, la intermitencia de las fiebres, delas cuales el prefecto registró ocho accesos en su diario personal durante 1921, lleva la percepción del daño en partes del cuerpo tanto en apariencia como en funcionalidad. De acuerdo con la línea de análisis de Strauss et al . (1999), esta percepción del daño corporal depende del área afectada, de su evolución y del impacto que tenga en la rutina de trabajo.

\section{AQUí SI LAS DIFICULTADES NO SON VEINTE, ES PORQUE PASAN DE DOSCIENTAS}

P ARALELA A LA HABITUACIÓN DE LAS FIEBRES, LOS "TRABAJOS" DEL PREfecto Arteaga surgen cuando se trata de materializar la infraestructura de la misión:

Necesitábamos embarcaciones. En esteasunto como en otros muchos; cuánto hay quetrabajar para sal ir con al go! es un desamparo, una falta de ayuda de todo el mundo, una escasez de toda clase de artículos, que hay que usar Paciencia con mayúscula y armarse de valor para considerarse uno solo contra mil obstácul os y confiar, después dela gracia de Dios, en sus solas fuerzas (APSJN, Urabá, Caja 3 Legajo XV, Diario de un misionero (inédito), José Joaquín Arteaga 19211922: 14. Subrayado en el original).

El "cuerpo vivido", o sea el sí mismo y el cuerpo que unificadamente actúan en el mundo, se escinde una vez aparece la enfermedad, con lo cual el cuerpo se constriñe, se opone al sí mismo, hasta configurar el "cuerpo objeto" (Gadow, en Garro, 1994: 104). El padre Arteaga entra en una nueva relación con su cuerpo, ya no un objeto asumido inconscientemente, sino un objeto del pensamiento consciente (Murphy, en Garro, 1994). Saca en claro de las primeras excursiones la imposibilidad de confiar en la ayuda de los "infelices negros": "Hoy prometí ante Dios y ante mi conciencia prescindir de ellos para siempre 
aprendiendo con tesón el arte de dirigir las embarcaciones de vela y preparando una de motor que es la que, al presente, nos lleva con rapidez de una costa a otra" (APSJN, Urabá, Caja 3, Legajo XV, Diario de un misionero (inédito), José Joaquín Arteaga 1921-1922: 50-51). Durante un tramo entre Pavarandocito y Dabei ba sus fuerzas se cotejan ante el entorno:

\begin{abstract}
Era un problema defuerzay habilidad atravesar aquellas cambroneras con el fusil debajo el brazo, la cabeza baja, tendido casi en la mula sin que lograra evitar, a pesar de todas mis precauciones, los golpes de los pal os y los arañazos de las espinas. Vez hubo que un bejuco se me atravesó por el cuello y me tendió cuan largo era sobre la silla logrando, antes de caer al suelo, romperlo con el fusil. En el paso del Mutatá, río muy caudal oso y violento, tropezó dos veces la mula y estuve a pel igro de ser arrastrado por la corriente (APSJN, Urabá, Caja 3 Legajo XV, Diario de un misionero (inédito), José J oaquín Arteaga 1921-1922: 83.
\end{abstract}

En esta época, el prefecto se esfuerza al máximo como trabajador competente; se desgasta físicamente y corre riesgos para salvaguardar su estatus, mi entras levanta la base de Puerto César en 1921, desde donde se exploraría el territorio de los indígenas kuna:

Una tierra sin caminos de herradura, o teniéndolo por tales pantanos y precipicios, sin vehículos para echarse sobre las aguas que, lejos de ser mansas, infunden terror y hacen víctimas frecuentemente de Ios atrevidos que se tiran a ellas; sin brazos para el trabajo; con un clima fuertey del etéreo; sin gentes que le tiendan la mano [...] Esto y mucho más que no alcanzo a decir, es el campo en el cual este señor Prefecto lucha tranquilo, Ileno de fe y hasta al egre, trabajando sin cederle un palmo a la debilidad ni a la desconfianza. Yo no sé profetizar, ni mucho menos; pero sí me atrevo a asegurar que triunfará. Si Dios no le da el triunfo a la fe y al sacrificio, ¿a quién ha de darlo?

Furtivamente me he enjugado varias veces lágrimas que me traicionan al ver los sacrificios que se impone y a que se entrega este ilustre Prelado. Para adaptar la casa queha de formar la primera planta misionera, trabajan él y el reverendo Padreque le acompaña [... ¡ iLlenos de fe y al egría ellos son los peones! (Carta al Director de El Católico, 17 abril de 1921, en Montoya, 1963 347). 
A partir de un viaje "desastroso" fija la autopercepción del daño corporal:

M.R.P. Severino y demás resignados oyentes:

Quizá noten en la letra al go más de temblor que de ordinario. Esto es debido a que ya las fiebres me van visitando de vez en cuando y dejan un tembleque en la mano que no hay manera de sujetar la pluma [...]. Pasamos hambre y sed, cal ores insoportables: bebimos aguas insanas de la que por esas costas Ilaman "agua gorda" que es una mezcla de dulcey sal ada, turbia y sin filtrar [...]. Tantos trabajos y fatigas sostenidas por más de un mes dieron al traste con mi salud y me atacaron unas fiebres violentas [...] estoy mejor, pero tengo mis recaídas y flaco como un esquel eto (APSJN, U rabá, Caja 2, Legajo XIII. Carta deJ oséj oaquín Arteaga a Severino de Santa Teresa, Puerto César, 26-VI-1921).

Pocas semanas después de recibir esta carta, el proprefecto Severino de Santa Teresa escribe a Roma y cita el fragmento de la carta del prefecto. Arguye que tal misiva "no necesita comentarios" y que ha sido "escrita sin sospecha de que llegue a manos de V.R. y demás superiores responsables" (AG, Misiones Urabá, Colombia en los fondos del Archivo general O.C.D., Correspondencia de los prefectos apostólicos, diciembre 1919-1976, carta de Severino de Santa Teresa a P. Guillermo, Síndico de las misiones, Frontino, 28-VII-1921). ¿Es esto un "trabajo mancomunado de esperanza", que intentaba convencer a los superiores de la importancia de la salud? Pienso que sí. Llama también la atención la repetida queja en la correspondencia sobre la invalidez de la mano ${ }^{15}$, prolongación de su intelecto, que el padre Arteaga ejercitó en medio de los azares de la vida misional: “[...] l o raro y admirable es que un hombre cansado después de sus correrías inauditas, a la luz de una vela o en el intermedio de una misión y otra, o en medio casi del delirio de la malaria, esté escribiendo historia y poesía" (Vallejo, 1976: 29).

La elaboración desu estado mediante símiles como el de "esqueleto", estar "medio muerto" o estar "hecho una calamidad" caracteriza en la correspondencia la cambiante percepción de sí mismo;

15 "Saludo con mucho agrado a su excelencia. Tengo fiebre en estos días y aunque tengo inválida una mano, yo mismo puedo dar respuesta a vuestra comunicación del 14 de octubre de 1921" (AG, Misiones Urabá, Colombia en los fondos del Archivo general O.C.D., Correspondencia de los prefectos apostólicos, diciembre 1919 1976, carta de José Joaquín Arteaga al Cardenal Prefecto de Propaganda Fide, Frontino, IVII-1922; original en latín). 
Arteaga percibió a fray Rafael dela Cruz como un "esqueleto", luego de que éste permaneciera por más de dos años en el golfo (APSJN, Jerarquía carmelitana, Superior provincial, correspondencia 1921-1926, carta de José Joaquín Arteaga a P. Ezequiel, Medellín, 21-IV-1926).

Severino de Santa Teresa persiste en su propósito de sensibilizar al generalato de la orden y a la jerarquía romana; poco después informa sobre la actividad del prefecto, quien recorre pueblos de las "mal sanas costas" donde "nunca un sacerdote ha entrado antes":

Nos consta que está muy quebrantado en su salud pues lleva seis meses en aquellos climas terribles. Lo hemos invitado varias veces para que venga a Frontino a restablecerse, pero siempre se excusa. Yo creo que no se atreve a venir aquí porque no es de su jurisdicción y no hay otro punto donde pueda reponerse. Urge pues, mi querido P. Gmo, la resolución deFrontino (AG, Misiones Urabá, Col ombiaen los fondos del Archivo general O.C.D., Correspondencia de los prefectos apostól icos, diciembre 1919-1976, Severino deSanta Teresa a Guillermo de San Alberto, Frontino, 18-VIII-1921 Subrayado mío) ${ }^{16}$.

En la línea de persuadir a sus corresponsales, fray Severino incluye en la misma carta una posdata, recogiendo un comentario del vicario provincial desde Medellín:

Aquí está la Madre Laura y nos ha contado los grandes sufrimientos de nuestros misioneros en Turbo. El padre prefecto estuvo con más de 4lgrados de fiebre; pero ya, gracias a Dios, está mejor. Todo esto, mi buen padre, sería bueno que lo

16. A fines de 1925 Propaganda Fide autorizó la estancia del prefecto en el convento de Frontino, cuando no estuviese en visita apostólica u otro oficio dentro del territorio de misión. Advierte que no es de buen recibo la residencia del ordinario por fuera del territorio de su jurisdicción y, por tanto, espera el menor uso posible de la facultad concedida (AG, Misiones Urabá, Colombia en los Fondos del Archivo General O.C.D., Permisos y licencias [Congregaciones romanas y superiores generales], Permisos de Propaganda Fide, carta a P. Giulielmo de S. Alberto Preposito Gen. dei Carmelitani Scalzi de Francesco Marchetti Selvaggiani Arcivescovo di Seleucia, secretario, protocolo N o. 880/25 Roma, XII- 19250 riginal en italiano). supieran en laS. Congregación, para que vean que no pedimos ninguna cosa injusta. Vale (Ibid. Subrayado en el original). 


\section{LAS MISIONERAS CABRAS}

A CONGREgACIÓn MISIONERA DIOCESANA FUndAdA EN 1914 EN DAbeiba (Urabá) por la antioqueña Laura Montoya, religi osa beatificada en 2004 por el Vaticano, compartió labores con Ios carmel itas descal zos entre 1919 y 1924. La madre Laura y el pre fecto Arteaga mantuvieron una relación conflictiva, por divergencias de concepción en el apostolado misionero. El prefecto censuró las "extralimitaciones en el ministerio" y las “tendencias poco conformes" al rol de la mujer en la propagación del Evangelio que a su juicio alentaba Laura Montoya (carta de Arteaga a Monseñor Crespo, 23॥-1923, citada en Mesa, 1999. 345 48). Pero cuando monseñor Arteaga vive episodios de enferme dad, desaparece la tirantez, la misionera se desempeña como cuidadora y él toma el rol de asistido, según consta en tarjeta enviada a la madre Laura en enero de 1924: "Saldré el 18 para empezar los ejercicios el 19 y terminarlos el 28, si le parece. Probablemente tendrá que hacer de enfermera porque tengo las piernas Ilenas de Ilagas. ¿No me habló de un depurativo excelente para la sangre?" (citado en Mesa, 1999. 329).

Las "extralimitaciones" de la congregación antioqueña de volvían Ios temores de los carmelitas, en una definida tensión de género:

Los padres se han asustado siempre de que no tengamos mi edo de ir a los mal os climas, pero no creí que eso fuera ir delante de ellos, porque ellos no estaban comprometidos a seguirnos. Los señores obispos Crespo y Toro me han mandado a hacer las fundaciones en I os mal os climas y luego han rogado a los padres que entren a Murrí, pero no los han obligado (Montoya, en Mesa, 1999. 309) ${ }^{17}$.

Los "mal os climas" eran justamente los lugares a donde se replegaban los indígenas embera de las vertientes del distrito montañoso -sur de la prefecturaanteel proceso decolonización de la frontera que transformaba el paisaje sel vático en pastizales y en fincas de café y al godón. En tanto, loskunadel distrito marítimo-norte de la prefectura-migraban hacia Panamá, dada la presión

17. Consta la comunicación del prefecto a la jerarquía eclesiástica colombiana sobre la provechosa labor de las hermanas catequistas "... en estas tierras de clima tan peligroso, que sólo ellas se han atrevido a desafiar" (Carta de José Joaquín Arteaga al Arzobispo Primado, Puerto César, 29-111-1922, citada en Mesa, 1999. 327). 
demográfica ejerci da sobre sus tierras por el campesinado venido de la llanura Caribe. La dinámica de los asentamientos indígenas tuvo distinta lectura por la misión foránea y por la congregación antioqueña: Ios frailes procuraron una estrategia conservadora para las fundaciones, con el bienestar de los operarios evangélicos en mente, al tiempo que Laura Montoya buscó adecuarse a la movilidad indígena con las "ambulancias misioneras", o fundaciones temporales enclavadas en la selva, hasta donde ll egaban las "misioneras cabras"18.

Ante la pobre oferta institucional, las misioneras antioqueñas cuidan de los frailes entre 1921y 1923 en las fundaciones de Turbo, Puerto César y Unguía del distrito marítimo y, en ese sentido, se amoldan a las expectativas de género ${ }^{19}$. Las catequistas son una de las audiencias que constatan las dificultades de los carmel itas en el golfo de Urabá y proveen un soporte de esperanza a las tribulaciones de los religiosos; hallándose en la capital del país, el prefecto recibe de una de el las la siguiente carta:

Mucha falta nos hace, muy sol a se véla casa apesar (sic) de estar llena de hermanas. Dios quiera tráernoslo

18. "Van de montaña en montaña, trepando o bajando, con alegre avidez, por hallar las habitaciones de los pobres indígenas, que se encuentran diseminadas de un modo desconsolador. Es hasta poético verlas emprender estas correrías: con hábito de tela gruesa para que resista, muchas veces sin conseguir su objeto, a las breñas y zarzales; con botas fuertes y altas para evitar el roce de las espinas y ponerse al abrigo de la picadura de animales ponzoñosos, amén de los barrizales, pues otra clase de calzado quedaría entre ellos; llevan gorros blancos, en verano, y de hule en invierno; cada una lleva un bastón, el primero resistente que encuentra para apoyarse $[. .$. Cuando han llegado al punto en donde la vía se hace intransitable, ja caminar con pata!, como dicen los indios. Entonces es cuando desempeñan con destreza y agilidad incalculables su oficio de cabras" (M ontoya, 1963 16).

19. El fraile Juan Evangelista escribe sobre las lauritas: "Con las hermanas viví en Turbo y en Puerto César. Estuve muy grave, según me dijeron. El primer sacerdote que me absolviera estaba a más de ochenta leguas, sin vías de comunicación y sin médico. Las hermanas me levantaron, a ellas, después de Dios, debo la vida [... ]", (citado en Mesa, 1999. 340). pronto, y muy sano y ya que digo esto no puedo menos querecordarlelo del médico pues ahora que está donde hay recursosfueramuy bueno quelos moviera pues la vida de Su Señoría es muy precisa (APSJN, Urabá, Caja 2, Legajo X. Carta de Hna. María del Santísimo a prefecto apostólico de Urabá, Puerto César, 8I-1923.

Las crisis de salud, evidentemente, también fueron sufridas por ellas y por el personal de servicio en la base de Puerto César. La atención a los enfermos, el transporte de los mismos fuera de la regi ón cuando se agravaban, la búsqueda de medicinas y de facultativos, presume una considerable inversión de trabajo en salud. Con todo, se logró acondicionar dicha base, aprovechando 
su ubicación estratégica y la sal udable brisa marina: "Lo cierto es que en ésta todos gozamos de buena salud. Las fiebres tan graves que he pasado, las he contraído siempre en las excursiones y al volver a casa desaparecen. Ahora con la lancha no habrá peligro ninguno, porque podremos ir al extremo de la prefectura en un día" (APSJN, Urabá, Caja 3 correspondencia (2a) $1921-1925$ carta de José Joaquín Arteaga a provincial Atanasio, Frontino, 25x-1921). El retiro de la congregación femenina se produjo en 1924 a causa de las contradicciones entre el prefecto y la superiora; fueron reemplazadas por las terciarias carmelitas venidas de Catal uña en 1925

\section{¿HÉROES EN LA SELVA?}

A NOCIÓN DE PERFORMANCE ALUDE A LA REPRESENTACIÓN DRAMÁTICA del sí mismo en la cotidianidad. Todos, no sól o cuando estamos enfermos, buscamos guiar las impresiones que suscitamos en los demás; la información se produce por medio de performances o actuaciones ante determinadas audiencias (Goffman, en Brodwin, 1994: 92). A sabiendas de que el dolor crónico es un desorden privado, el sufriente recurre al "manejo de la impresión" en público. El enfoque dramatúrgi co permite entender en el caso estudiado, cómo Arteaga desarrolla una conciencia sobre la presentación del sí mismo, en instancias de la acción social: el círculo de sus inmediatos colaboradores, la ciudadanía, la jerarquía carmelitana, el clero regional y, por supuesto, la posteridad sin que esto signifique, siguiendo a Brodwin (Op. cit.), que haya hecho del dolor una actuación ni que lo produjese a voluntad.

La representación de Arteaga como héroe surge a fines de 1921 , cuando el grupo de misioneros encabezado por él resuelve dimitir, a consecuencia de la decisión de la Santa Sede que autorizaba a Frontino como sanatorio, descartando la capitalidad. Los frailes elevan su renuncia ante el definitorio provincial, no sin antes advertir que "Todo lo que sea demorarse en este asunto es exponer la vida de los Misioneros" (APSJN, Urabá, correspondencia (2a) 1921-1925 carta de José Joaquín Arteaga a Provincial, Frontino, 14-XII-1921).

Dentro de la ascética carmelitana -uno de los caminos de la vida espiritual-, la enfermedad es un medio de purificación 
frecuente usado por Dios, ante la cual no hay otra regla que dar sino la virtud de la paciencia y el amor al sufrimiento (Crisógono de Jesús Sacramentado, 1949: 104). Pese a que el misionero suscribía esta interpretación, las repetidas crisis de salud Ilevan a dudar de la validez del "heroísmo continuado":

[...] de manera que aquí la obediencia recae sobre actos heroicos y la fragilidad humana no está siempre para obedecer heroicamente ni es posible que una orden religiosa sea capaz de sostener una Misión donde todos, absolutamente todos, hayan de ser héroes. El heroísmo personal es muy hermoso y yo creo que hasta el presente se ha prodigado en el Urabá a costa de la salud: pero si ha de ser estéril, si no se afianza en una organización que asegure la vida de los Misioneros ¿quién podrá sostener semejante Misión? Ocho meses pasé en las costas mortíferas del golfo y estuve a punto de muerte dos veces con $41^{\circ}$ de fiebre, y quién me quitará el paludismo que lo llevo ya en los huesos? (APSJN, Urabá, correspondencia (2a) 1921 1925 carta de JoséJoaquín Arteaga a Provincial, Frontino, 14-XII-1921 Subrayado mío).

La crítica a los límites de la obediencia religiosa reaparece cuando Arteaga indica que le resulta "muy duro" imponer a sus operarios las tareas en la región; en este caso, el prefecto explica cómo aminora el impacto de la morbilidad entre sus subal ternos:

[...] por tanto yo solo atiendo estos lugares de muerte aunque sé que voy a sufrir la muerte o gravísimas enfermedades. Sería total mente descabellado pensar que se puede mandar por mucho tiempo alguna cosa en esas condiciones. Además no tenemos ni esperanzas de que se pueda enviar un nuevo operario a estas misiones a que se consuman en este ambiente de fiebre, calor y peligros (AG, Misiones Urabá, Correspondencia de los prefectos apostólicos, diciembre 1919-1976, carta de José Joaquín Arteaga al Cardenal Prefecto de Propaganda Fide, Frontino, I-VII-1922. Original en latín).

El definitorio provincial, instancia favorable inicialmente a la cesión de Frontino a la misión de Urabá (Unzueta, 2001: 106107) confiesa su "gran contrariedad" por la negativa de la Congregación de Propaganda Fide a este respecto, pero, así mismo, disiente de la renuncia: 
Entiendeel Ven. Def. Provl. que una resolución semejante de los PP. Misioneros en las actuales circunstancias, cuando el Santo Padre en gravísi mo y laudatorio documento nos exhorta a ser dignos hijos de la gran Celadora de la gl oria de Dios [... ] y cuando tanto se habla en todas partes de la acción Misional del Clero en especial del regular, sería del mal efecto y daría ocasión a los altos poderes Eclesiásticos y Civiles para juzgar a la orden poco favorablemente respecto de su espíritu misional y de sacrificio (APSJN, Jerarquía carmelitana, Superior provincial, correspondencia (2a) 1921-1925, carta de Definitorio Provincial al Prefecto Apostólico de la Misión de Urabá y PP. Misioneros, Pamplona, 15V-1922. Subrayado mío) ${ }^{20}$.

La orden carmelita, entonces, cierra filas al rededor del compromiso adquirido en 1905 por la provincia de San Joaquín de Navarra, cuando aceptó fundar misiones en Chile, Perú y CoIombia (Álvarez, 1998). La implantación de la orden en el país dio pie a un florecimiento vocacional autóctono, que facilitó el envío de personal hacia conventos carmelitas en Centroamérica. Ceder ante la renuncia de los misioneros de Urabá habría significado desmantelar un campo promisorio. Aunque el provincial Atanasio del Corazón de Jesús reconocía el cansancio del prefecto por "trabajar en aquel clima ingrato", consideró "al go radical" Ia renuncia: "Dada nuestra poca abnegación, preferiría en verdad no tener esa $\mathrm{Mi}$ sión, pero habiéndola adquirido, entiendo que tenemos un compromiso de honor de sostenerla poniendo todos Ios medios a nuestro al cance" (Carta a P. Ezequiel, Marquina, 11-I-1922, en Un-

20. En el tercer punto de esta carta, el definitorio se compromete con "recursos necesarios para su congrua sustentación" de modo que la misión llegue "a su mayor florecimiento" (APS) N, Jerarquía carmelitana, Superior provincial, correspondencia (2a) 1921-1925 carta de Definitorio Provincial al Prefecto Apostólico de la Misión de Urabá y PP. Misioneros, Pamplona, 15V-1922). zueta, 2001: 114-115).

En el ámbito nacional también se rechazó la dimisión, preocupante para el viceprovincial: "Mehan dicho que el P. Prefecto envió su dimisión a la Sagrada Congregación: si andamos así nos vamos a acreditar de serios" (APSJN, Jerarquía carmelitana, Superior Provincial, correspondencia 192126, carta de fray Miguel del Niño Jesús Arangoa a Provincial, Villa de Leyva, 10-v-1922). Pero ninguna de las instancias que intervenían en el asunto se pronunció sobre la escasez de personal, de cuya solución dependía en parte el buen funcionamiento de la prefectura. En efecto, monseñor Arteaga planteó que era indispensable un personal 
numeroso ya que sól o así se cumpl iría con “la remuda trimestral en puestos peligrosos". Esto implicaba disponer de veinte misioneros, en vez de los diez integrantes para ese momento (APSJN, Urabá, correspondencia (2a) 1921-1925, carta de José Joaquín Arteaga a provincial, Frontino, 14-XII-1921). La "remuda" o "trasiego" de los operarios era parte del "trabajo cotidiano en salud", que hubiese permitido recuperar fuerzas después de los cortos pero intensos periodos del ministerio en Urabá (APSJN, Jerarquía carmelitana, Superior provincial, correspondencia 1921 1926, carta de Pascual de Santa Teresa a Ezequiel de S.C. de Jesús, Frontino, 25-11-1926).

El aumento de personal dependía del incremento del presupuesto de la prefectura, cuestión planteada con un dejo de ironía:

Es una escasez necesaria, porque si con la asignación susodicha apenas podemos vivir 10 misioneros ¿con quéjusticia vamosa exigir a la Provincia que aumente el número? [... ] si no envían gente, los actuales o perecemos o nos inutilizamos muy pronto; y si envían tendrán que pasarlo mal por falta de recursos (APSJN, Urabá, correspondencia (2a) 1921-1925, carta de José Joaquín Arteaga a provincial, Frontino, 14-XII-1921).

Luego del rechazo de la renuncia, monseñor Arteaga cambia su estilo de trabajo. Desiste de su petición, pero hace la sal vedad de que "Frontino es absolutamente necesario para la misión de Urabá, sea quienquiera que la dirija". Propone un sistema de "partidas volantes" quea los pocos días permitía volver al punto de partida para reponerse. Esta estrategia, producto de "dos años de terrible experiencia de tanteo" se acercaba al método itinerante de evangel ización de las catequistas anti oqueñas que criticó en su momento, y asumía la dificultad de una acción parroquial estable, puesto que "ni los pueblos están preparados para ello ni el clima permite semejante ministerio" (APSJN, Urabá, Caja 3 Legajo Xv, Diario de un misionero [inédito], José Joaquín Arteaga 1921-1922: 98).

El prefecto continúa envuelto en las actividades de su cargo, con viajes de un distrito a otro y también a Medellín y a Bogotá. Diríase que monseñor Arteaga vive la rutina con y a pesar de sus padecimientos; se ha adaptado -o resignado- a las dificultades, al tiempo que recibe el soporte de las redes sociales de la misión. En 1924 su prestigio estaba consolidado en las instancias eclesi ásticas 
y gubernamentales en los nivel es local y nacional, y también entre los indígenas kuna. Desde 1922 estos superaron la reticencia inicial frente al prefecto y lo consideraban ahora su protector en el marco de gestiones con el gobierno nacional relacionadas con sus derechos territoriales, amenazados por los colonos. En esa época reporta lo siguiente: “Mañana sal go de nuevo para Dabei ba y el golfo, después de una larga correría de tres meses, en que a pesar del considerable trabajo que he tenido, me he repuesto notablemente de sal ud", si endo una de las escasas veces en que el prefecto deja constancia de sentirse a sus anchas (APSJN, Urabá, correspondencia (2a) 1921-1925 carta de J osé Joaquín Arteaga al provincial, Frontino, 9-II-1924).

El curso de su padecimiento sirve de molde para que otros misioneros elaboren el propio: "Amadísimo padre: En el último correo todavía no podía escribir [...] mes y medio con fiebre cada dos días me originaron la dilatación en el estómago por el esfuerzo para vomitar y quedé sin poder discurrir, comer ni digerir (sin cabeza, estómago ni hígado). Lo mismo que el Prefecto dos meses antes". El fraile toma conciencia de su debilidad frenteal arrojo y la fortal eza del prefecto, narra las peripecias de éste para cruzar el mar Caribe entre Puerto César y Unguía, evento en que las fiebres son "casi infalibles e inevitables" por el trasiego de las aguas: Ia "vigésima parte de eso produce en mí fiebres de un mes", concluye (APSJN, Urabá, Legajo XV, Diarios de la Misión, anexa a Diario de El Carmelo. Congregación misioneras Madre Laura. Carta de Juan Evangelista del Santísimo Sacramento a Severino de Santa Teresa, Turbo, 16-X-1922).

En la heroización del prefecto participa la prensa antioqueña, que destaca su veteranía en la región de Urabá "Iuchando a brazo partido contra la natural eza hostil" (La Defensa, 2 de marzo de 1926: 1, 9). Durante su último año de vida, el prefecto se sumó al proyecto de construcción de la carretera al mar, como miembro de la junta propulsora de la vía. Atendiendo a un Ilamado de urgencia a Medellín, viajó para hablar sobre el proyecto de la carretera, lo cual supuso renunciar al descanso de un par de semanas luego de "una gira en visita pastoral bastante penosa por las montañas" (APSJN, Jerarquía carmelitana, Superior provincial, Correspondencia 1921-1926, carta de José Joaquín Arteaga a Ezequiel del Sagrado Corazón de Jesús, Medellín, 21-ıv-1926). Desde su triple condición de religioso, extranjero y profundo conocedor de la región, fustigó a los antioqueños para que dieran 
curso a la conexión terrestre de Medellín con el mar Caribe, favorable a la acción misional en Urabá. El discurso pronunciado en Medel lín semanas antes de su muerte refería cómo los padecimientos estructuraban su biografía personal:

Hermosas pal abras del Señor Prefecto A postólico en la manifestación del jueves.

[...] Me considero orgulloso de trabajar en un pedazo de tierra antioqueña y si bien mis ideales son ultraterrenos siento la responsabilidad de amar todo lo grande, lo noble y lo bello, como emanado de la Cruz del Redentor, fomentarlo y mejorarlo y aún relacionarlo con los intereses materiales, porquetambién la tierra es el pedestal dela gloria deDios. Tengo la piel tostada por el sol tropical, la vista disminuida por los reflejos Iuminosos del golfo de Urabá; por aquel los caminos hedejado con mi sudor jirones demi vida, heseñal ado varias veces la arena delas playas con huellas ensangrentadas; la fiebre palúdica ha sido mi inseparable compañera durante dos años, he naufragado tres veces, como San Pablo... y ni un solo momento con la gracia de Dios, ha decaído el entusiasmo de mi corazón, porque he trabajado por Cristo y por Antioquia!

Después de seis años de sudores y fatigas por el Urabá me considero con derecho a presentarme (El Correo Liberal, lunes 8 de marzo de 1926, No. 3284: 2).

Luego de esta intervención, la salud del prefecto decae hasta el punto de verse obligado a permanecer en la ciudad por una "enfermedad del hígado". La disrupción biográfica que conlleva la enfermedad se plasma en una de las últimas cartas enviadas al provincial, en que le comunica el éxito obtenido en la Asamblea departamental: "Y cuando estaba en el apogeo de mi gloria, me da el ataque al hígado y me tiene un mes en cama! Ahora empiezo a levantarme, y ya ve por el mal pulso, que aparece en la letra, que todavía no estoy bien" (APSJN, Jerarquía carmelitana, Superior provincial, correspondencia 1921-1926, carta de J oséj oaquín Arteaga a P. Ezequiel, Medellín, 21-ıV-1926).

Trasladado al sanatorio de Frontino, monseñor Arteaga ventila toda suerte de asuntos administrativos con el pro-prefecto Severino, consignando en la correspondencia los síntomas que lo aquejan: 
Muy amado P.:

En mi poder las suyas, no pude desde Medellín contestarlas por un tembl or conti nuo que tuve hasta última hora y me impedía tomar la pluma y por el inmenso trabajo de juntas y compromisos que nos absorbía el tiempo y la atención. Parece que no han estado nunca enfermos para juzgar tan duramente a los ausentes que en 40 días no pueden hacer nada. Todavía en el viaje-que es el más penoso quehe hecho en mi vida- a las dos horas de montado ya iba temblando y con dolores en todo el cuerpo (APSJN, Urabá, Caja 4, correspondencia (2a) 1921 1925 carta de JoséJoaquín Arteaga a Severino de SantaTeresa, Frontino, BV-1926).

\title{
UNA MUERTE SANTA Y EJEMPLAR
}

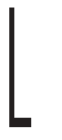

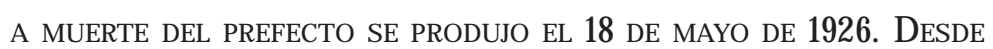
la documentación y las entrevistas a dos sobrevi vientes, pue den bosquejarse las jornadas finales en las cuales el prefecto guarda la compostura pese al dolor:

\begin{abstract}
A los cuatro días de haber llegado a ésta sintió cólicos hepáticos; Ilamamos a los doctores, pero desde un principio desconfiaron de su salvación porque no sól o el hígado sino las vísceras todas las tenía muy congestionadas y en una inercia completa que imposi bilitaban todaacción médica (APSJN, Jerarquía carmelitana, Superior provincial, correspondencia 1921 1926, carta de Leonardo de San Joséa P. Ezequie, Frontino, VI-09-1926).
\end{abstract}

El padre Arteaga realiza gran cantidad de trabajo en su condición de moribundo: envía por el pro-prefecto Severino a Dabeiba para enterarlo de los últimos asuntos de la misión, le hace entrega del crucifijo que portaba con el encargo expreso de remitirlo a su madre, recibe los auxilios espirituales y bendice al personal religi oso que lo rodeaba en su lecho de muerte (AHCPM, Carmelitas Misioneras, Signatura 096/01/a, Historia Provincial, Diario de la Delegación, 1925-1976). Al momento de expirar dice con los brazos extendidos: "Miro al Cielo y veo acercárseme. Ofrezco mi vida, mi alma, mi cuerpo por mi amada Orden Carmelita y por la querida Misión de Urabá. Vosotros Padres Carmelitas, os toca Iuchar en este mundo Ileno de peligros" (La Defensa, 20 de mayo de 1926. No. 1196). Y añadió: “¡Virgen Santísima, Madre mía del Carmen! Cuán agradecido 
estoy a tantos beneficios como me habéis hecho" (AHCPM, Carmelitas Misioneras, Si gnatura 096 A/01/a, Historia Provincial, Diario de la Del egación 1925-1976). La única testigo de la agonía recuerda así el momento:

\begin{abstract}
El padre estaba muy enfermo del hígado, el día de la Ascensión (jueves) nos estuvo confesando y cel ebrando misa, ya se enfermó grave, ya tenía el hígado deshecho. Yo le pedí al padre permiso para pedirle al Señor que me dé lo que usted sufre "no hija, no", dijo él. "Que no me entierren antes de que me descomponga". Al momento que expiró, le salió por la boca todo el hígado deshecho, el padre Amancio y la hermana Ester lo acostaban boca abajo en la cama después de muerto, y unas palanganadas que salían ... en la capilla ardiente estaban constantemente limpiándole la nariz que le supuraba (María Ángel es I mízcoz, carmelita mi sionera. Entrevista. Pamplona, 4-XI-2000).
\end{abstract}

La ciudadanía, preocupada por lo que ocurría en la clausura, se mantenía al erta al desenlace: "Cuando se murió, todo el pueblo se puso en banderas negras" (Ángela Góez de Gaviria. Entrevista. Frontino, 9-XII- 2000).

\title{
A LO EXTRAORDINARIO DEL PADRE JOSÉ JOAQUIN NADIE ESTÁ OBLIGADO
}

D ESDE LA VISIÓN PROVIDENCIAL DE LA HISTORIA, LA MUERTE DEL PREfecto se representa como un contrato entre "el buen Jesús" y un "mártir del deber", sellado a comienzos de la obra apostólica de la prefectura (APSJN, Biográficas 5 Carta de Amalia de Santa Margarita C.D.M. a Pedro María Duñabeitia o.C.D., Medellín, 19-1II-1952). Se descarta la improvisación en la el ección de pastores y evangelizadores, aunque se admite que su formación y perfeccionami ento transcurren por los "caminos humanos":

Los héroes y los santos tampoco son de generación espontánea, sino que, pesando sobre ell os un designio superior, necesitan su calvario como entrenami ento lleno de tropiezos y decruces. De esto no podía ser excepción el Padre José Joaquín Arteaga, si era que había de ser pastor, evangel izador, héroe y santo (Vallejo, 1976: 20). 
El desenlace biográfico del padre Arteaga refrenda el sacrificio de los "operarios evangélicos" en aras de la expansión misionera, y la prensa regi onal asume su muerte como "un tributo a la madre tierra":

Este vasto territorio, de clima deletéreo, inculto en su mayor parte, monstruoso y poblado de plagas, sin vías de comunicación y habitado por negros mestizos e indios en estado semi-salvaje, fue el que le tocó en suerte apacentar, catequizar y endi lgar por la vía de la civilización y el progreso, delas costumbres morigeradas y del trabajo enaltecedor, al benemérito carmelitano (El Correo de Colombia, Medellín. “Muertos notables”, 21de mayo de 1926: 1 No. 3344).

Urabá, "sepulcro de muchos religi osos", absorbió buena parte de las incul paciones asociadas al fallecimiento de monseñor Arteaga. La culpa, la crítica y la justificación son procesos social es esenciales que se aplican a la ocurrencia del infortunio y de la enfermedad, fundados en la idea de queel cuerpo-y aqueIlo que le sucede- es un medio para ejercer el control social. Lejos de ser patrimonio de comunidades marginales, la inculpación se presenta con fuerza en sociedades al tamente organizadas y ni siquiera el propio enfermo escapa a su carga (Douglas, 1998). Alguna interpretación, por ejemplo, sugirió “la propensión a sobrepasar el límite" por parte del prefecto, o parafraseando a Charmaz, interpretó la muerte como resultado de la intención de Arteaga por proteger su "estatus moral":

El P. José Joaquín Arteaga no sabía negarse a nada. Cuando iba a Medellín a descansar y cambiar un poco de clima y ambiente, buscandoalivio al paludismo del gol fo deUrabá, lo cosían material mente con compromisos oratorios. El arzobispo de Medellín, monseñor Caicedo no veía esta prodigalidad con buenos ojos, y precisamente, por lo mucho que lo estimaba. Tanto, que al guna vez dijo que había pensado reservarse él los permi sos del P. Prefecto, avocándolos (sic) directamente a su persona, a fin de que no abusaran de él. Había venido, a curarsey reponersey no a dar conferencias o echar sermones en cual quier iglesia o sal oncito. Fruncíael ceño cuando leía su nombre en las columnas de los periódicos. Presentía lo que iba a pasar y se interesaba mucho por su salud (Pascual de Santa Teresa, 29de enero, 1960, en Restrepo, 1990: 31).

La Congregación de Propaganda Fide inició el proceso de conformación de la terna para la elección del nuevo prefecto 
apostól ico a los pocos días del insuceso, mediante oficio encabezado por condolencias por la "imprevista pérdida" del prefecto (AG, Misiones Urabá, Colombia en los Fondos del Archivo General O.C.D., Permi sos y Licencias, Congregaci ones romanas y Superiores generales. Permisos de Propaganda FIDE, de Francesco Marchetti Arcivescovo di Seleucia, secretario al Prepósito General Guillermo de San Alberto. Protocollo No. 1840/26 21-v-1926. Original en italiano). Monseñor Toro, "enemigo jurisdiccional" del padre Arteaga, escribió: "Urabá tendrá otro Prefecto; pero no otro P. Arteaga" (APSJN, Jerarquía carmel itana, Superior provincial , correspondencia 1921-1926, carta de Juan Evangel ista del Santísimo Sacramento a Superior provincial, Urama, 32-v-1926).

\section{REFLEXIÓN FINAL}

A VIDA del pREFECto ARTEAga en URABá permite comprender de qué modo el padecimiento actúa como pieza de las ne- gociaciones y forcejeos en una situación social dada. La suya es una trayectoria de padecimiento expuesta ante varias audiencias y estructurada por el alegato en pro de la salud, la presión por Frontino y la ampliación del el enco de misioneros. Monseñor Arteaga se sobrepone desde los inicios de su gestión a la enfermedad, y antes que un presumible descenso en el ritmo de trabajo exigido por la dirección de la prefectura apostólica, exhibe su capacidad para controlar, con escasa ayuda médica, los episodios febriles, la debilidad y las afecciones hepáticas que según el consenso médico de la época y del propio Arteaga resultaban dela cronificación del paludismo en las selvas y costas hiperendémicas de Urabá. El prefecto desarrolló estrategi as para mantener la apariencia de normal idad, resguardar el sí mismo, ajustar su desempeño a las presiones ambientales y proteger el bienestar de subalternos.

El ritmo que imprimió a los diversos frentes de la jurisdicción misional resalta en la documentación, donde el apretado examen de los asuntos de la prefectura está ensamblado por una retórica del sufrimiento que asume a la región como un entorno de muerte. Se ratifica el rol del padecimiento en la gestión de la realidad social, y su proyección -hacia adentro y hacia fueracomo lenguaje constitutivo del proyecto apostólico de Urabá y 


\section{Revista Colombiana \\ de Antropología

de la figura del prefecto en particular. La capacidad de sacrificio, con exposición permanente al insal ubre entorno, irrigó los discursos de la sociedad civil regional y nacional, medió los vínculos entrela opinión pública y la misión carmel itana y atemperó las contradicciones con Ios religiosos locales. La propaganda misionera recoge extensamente la retórica del padecimiento misional, que moviliza el apoyo financiero para las misiones de ultramar. La queja, proyectada hacia las audiencias religiosa y civil de la escena misional de la época, solidifica un proyecto que necesariamente se encarnó en la identidad personal delos misioneros. Y digo necesariamente, porqueera cuestión de merecer con el padecimiento la salvación de las almas. Desde los al bores del cristianismo, mártires y santos han ofrecido testimonio de dolorosas experiencias corporales, que reactualizan el drama dela pasión de Cristo. Los sufrimientos funcionan a modo de sal voconducto para la reproducción del universalismo de la iglesia, donde quiera que ésta se implante. El "insalubre" territorio de la misión, fue un lugar más para cumplir la promesa de sufrir a cambio de ganar al mas.

La confianza y el abandono del sujeto en la Providencia divina se construye en los térmi nos fijados por la visión de la historia, que toma como propósi to básico y modelo de la historia el desi gnio divino sobre la sal vación del hombre (Weintraub, 1991: 19). Los sucesos cotidianos, incluida la enfermedad, son parte del trazado de la voluntad divina en las existencias individuales, y esta creencia confiere sentido a los padecimientos, vividos como "pruebas del Señor". Mediantela escritura, se conjura la distancia que separaba el enclave misionero de las ciudades colombianas y de Europa, hasta recrear en el destinatario una vívida impresión de los padecimientos. Los rel atos presentes en los diarios, en el epistolario o en discursos publicados posteriormente, sustituyen a los síntomas por la dramatización de las vicisitudes y por una retórica que apelaba al reconocimiento social, hasta obtener de la audiencia la ratificación de una actuación heroica. Para que cobre val or social, el testimonio requiere siempre de una audiencia: en la primera mitad del siglo veinte, el consenso sobre los arrojados mi sioneros que se debatían en territorios de frontera en Antioquia y que entregaron su vida por "Ia querida misión de Urabá", había cal ado en círculos de la sociedad colombiana y, por supuesto, de la española. La misma impresión domi naba en las instancias provincial y gene- 
El camino del santazo. La narrativa del padecimiento misionero en Urabá

ral de la orden carmelita y del pontificado, donde se hallaba normalizada.

Al desmarcarse de los preceptos de obediencia y con su crítica a la "mansedumbre" mi sionera, Arteaga presiona por mejores condiciones de permanencia en la región, con el respal do de los frailes a su cargo. Haciéndolo quiso intervenir el curso de la enfermedad con el control de Frontino, dadas las garantías de reposición de la salud que deparaba esa población. Durante los tres primeros años de funcionamiento de la prefectura apostóli$\mathrm{ca}$, el reclamo se presentó a los superiores de la orden y de Propaganda Fide, con una intensi dad que final mente resul tó i nútil, pese a que aún en 1937 los frailes carmelitas insistían en Frontino. Las míni mas posibili dades de haber obteni do dicha plaza se esclarecen al examinar la reducción del territorio diocesano de Santa Fe de Anti oquia en 1917, trasfondo de los intereses puestos en juego por la contienda jurisdiccional entre la misión foránea y el clero local. Así mismo, expresa el deseo de los misioneros por controlar un oasis en el "inculto" territorio. El conflicto con los religi osos local es involucró una tensión de género frente a Laura Montoya, fundadora dela congregación de mi sioneras antioqueñas. Únicamente en la arena del padecimiento se destraba el enfrentamiento entre ella y el prefecto, cuando cumplen Ios roles de cuidadora y asistido, respectivamente. El mensaje implícito en el apostolado de las antioqueñas asumía frontalmente los riesgos, al go inaceptable para los carmelitas.

La coyuntura de la renuncia en 1921 movilizó diferentes interpretaciones sobre el heroísmo y el honor, que diluyeron la demanda básica de los misioneros por mejores condiciones de salud y de trabajo. La dimisión de los misioneros supuso, temporalmente, el descenso del estatus moral del prefecto, por la "poca abnegación" que leyeron en su actitud los superiores carmelitas. A la vuelta del correo, las al forjas estaban Ilenas de sentimientos de conmi seración y de llamados a la obediencia, pero poco más que eso. El orden institucional no cede a las presiones misioneras y resuel ve la continuidad de la prefectura apostólica de Urabá por el sacrificio del personal designado. El prefecto acepta la negativa y permanece como primera autoridad de la prefectura, hasta morir. En contraste con los casos trabajados por la investigación en enfermos crónicos, que ven la enfermedad como una "agresión ontológica", en el caso abordado por este artículo la visión providencial de la historia recorta la biografía personal, y 
al hacerlo imprime un profundo sentido religioso a los padecimientos. Al poco tiempo de hallarse en Urabá, el prefecto asumía su desti no como inexorable: "yo sé que voy a sufrir la muerte y gravísimas enfermedades...". Al escribir esas líneas había emprendido ya el "camino del santazo", y en el trayecto emergen los signos del desenlace: la zozobra de las mi si oneras, las súplicas de fray Severino ante la jerarquía carmelitana o los presentimientos del arzobispo de Medellín, que hacen eco a la pasión del prefecto en las trochas y costas de Urabá.

Cuando en 1926 delinea retrospectivamente en público la evolución de su carrera, monseñor Arteaga produce una perspectiva favorable de sí mismo, basada en su entereza moral para superar los escollos de la enfermedad y de los accidentes. El trabajo en Urabá se realza con "Ios sudores y fatigas" del apostolado, que confieren legitimidad a su actuación y constituye el balance moral de su gestión, sellada por la muerte dos meses después.

Paradójicamente, el esquivo Frontino al berga sus restos en la actualidad, en un mausoleo del cementerio municipal. El mismo que divisó Pablo del Santísi mo Sacramento desdela cima de la cordillera antes iniciar su descenso hacia la población por allá en 1930 y en cuya guarda se movilizaron los pobladores, cuando corrió el rumor, hace algunos años, de que serían trasladados a Medellín. Su memoria rotura el pueblecito de Villa Arteaga, en la vía que conduce hacia el mar.

\section{Bibliografía}

Álvarez, Óscar. 1998. Misiones y misioneros vascos en Hispanoamérica, 1820 - 1860. Labayru Ikastegia. Bil bao.

2001 “Notas sobre la etapa más desconocida de un político y escritor vasco: Jon Andoni I razusta, de parl amentario a mi sionero en Perú (1950-1952)". Revista de la Fundación Sancho el Sabio. 14.

Aristimuño, José. 1926. “La vidafecunda deun héroe". Nuestro misionero.17. Año III. Septiembre-octubre.

Arrizabalaga, Jon. 2000. "Cultura e historia de la enfermedad". En Enrique Perdiguero y Josep M. Comelles (eds). Medicina y cultura. Estudios entre la antropología y la medicina. Edicions Bellaterra. Barcelona. 
Arteaga, José Joaquín. 1921 “Diario de un misionero”. En Diarios de la misión (manuscrito). APSJN, Urabá, Caja 3 Legajo XV.

Bogotá.

Arteaga, José Joaquín. 1925 “Discurso en la sesión inaugural del Congreso de misiones". En Varios. Congreso y exposición nacionales de misiones católicas. Minerva. Bogotá.

Berger, Peter. 1971 Para una teoría sociológica de la religión. Kairós. Barcelona.

Bernardino del Niño Jesús. 1945 "San José de Turbo (de nuestras mi siones carmelitanas en Urabá)". Revista Carmelitana. 251. Año XXII. Enero.

Botero, JuAn (PBro). 1980. Monseñor Francisco Cristóbal Toro o el sentido de una lucha. Ediciones Centro de Historia San José de Ezpeleta de Sonsón. Medellín.

Brodwin, PAul E. 1994. "Symptoms and social performances: The case of Diane Reden". En Mary-Jo del Vecchio Good et al. (eds). Pain as human experience: An anthropological perspective. University of California Press. Berkeley.

Charmaz, Kathy. 1999. "Stories of suffering: Subjectivetal es and research narratives". Qualitative Health Research. 9 (3).

Córdoba, Juan Felipe. 2001 “Comunidades religiosas masculinas en A nti oquia, 1876-1940". Tesi s de grado para optar al títul o de magíster en historia. Universidad Nacional deColombia, facultad deciencias humanas. Medellín.

Crisógono de Jesús Sacramentado. 1949. Compendio de ascética y mística. Ediciones dela Revista de Espi ritual idad, PP. Carmel itas Descal zos. Madrid.

De Kempis, Tomas. 1999. Imitación de Cristo. Editorial Porrúa. México.

Douglas, MARY. 1998. Estilos de pensar. Gedisa. Barcelona.

FERNÁNDEZ, JoRge IVÁN, MXY. 2001 La seducción del África. Relatos de un misionero. Nueva Era. Medellín.

Fernández de Mendiola, Domingo Á. Misión apostólica y misionera del Carmelo Teresiano (en prensa).

Gadille, Jacques y Zorn, Jean François. 1995 “Le projet Missionaire”. Histoire du Christianisme. Jean-Marie Mayeur, Charles et Luce Pietri, André Vauchez, Marc Venard (sous la direction de). Tomo XI: Libéralisme, industrialisation, expansion européenne (1830-1914). Desclée. París.

GÁlvez, AídA. 2003 “Por obligación de conciencia. Los misioneros del Carmen Descalzo en Urabá (Colombia)". Tesis doctoral. Programa 
de doctorado en antropología de la medicina. Universitat Rovira i Virgili. Tarragona (inédito).

Garro, LindA. 1994. "Chronic illness and the construction of narratives". En Mary-Jo del Vecchio Good et al. (eds.). Pain as human experience: An anthropological perspective. University of California Press. Berkel ey.

Gerbi, Antonello. 1960. La disputa del Nuevo Mundo. Historia de una polémica. 1750-1900. Fondo de Cultura Económica. México.

Gusdorf, Georges. 1991 “Condiciones y límites de la autobiografía”. En A. Loureiro (coord.). La autobiografía y sus problemas teóricos. Suplementos Anthropos. 29.

Instructiones Missionum Ordinis Carmelitarum Discalceatorum. Romae. Typis Polyglottis Vaticanis. 1913

Kleinman, Arthur. 1988. The illness narratives. Suffering, healing and the human condition. Basic Books. Nueva York.

Kleinman, Arthur et al. 1994. "Pain as human experience: An introduction". En Mary-Jo del Vecchio Good et al. (eds). Pain as human experience: An anthropological perspective. University of California Press. Berkeley.

Le Breton, David. 1999. Antropología del dolor. Seix Barral. Barcelona.

López, Olga y Blair, Silvia. 2002. "Relatos de la malaria”. Revista Universidad de Antioquia. 268. Abril-junio.

Mercado, Francisco Javier. 1996. Entre el infierno y la gloria. La experiencia de la enfermedad crónica en un barrio urbano. Universidad de Guadalajara. Guadalajara.

Mesa, Carlos E. 1999. Laura Montoya. Una antorcha de Dios en las selvas de América. Cargraphics. Medellín.

Montoya, Laura. 1963 Cartas misionales, 1915 1922. Editorial Coculsa. Madrid.

Moriones, ILdefonso. 1978. El Carmelo Teresiano. Páginas de su historia. Ediciones El Carmen. Vitoria.

1997. El Carmelo Teresiano y sus problemas de memoria histórica. Ediciones El Carmen. Vitoria.

Muñoz, Emilio. 1920. Contribución a la terapéutica del paludismo. Editorial Félix de Bedout e Hijos. Medellín.

ILDElfonso de Santo Domingo. 1879. Vademecum de los hermanos novicios descalzos de la Beatísima Virgen María del Monte Carmelo. Opúsculo hábilmente compilado de la Regla, Constituciones é instrucciones de la expresada orden y de las mayores obras ascéticas 
por un maestro de novicios de la misma Sagrada Religión con autorización de los superiores y traducido del latín al castellano con igual autorización por el P. Fr., Ildelfonso de Santo Domingo, también Carmelita Descalzo. Bilbao.

Pablo del Santísimo Sacramento. 1944. Al amor de los Karibes. Relieves de una vida misionera. Ediciones El Carmen. Vitoria.

PujadAs, JuAn José. 1992. "El método biográfico: el uso de las historias de vida en ciencias sociales". Cuadernos Metodológicos. 5 CIS. Madrid.

Plummer, Ken. 1989. Los documentos personales. Sigl o XXI. Madrid.

Restrepo, Bernardo. 1979. “La orden carmelitana en Colombia. Síntesis histórica". En Textos de formación carmelitana. 7. Ediciones ECCO (Ediciones Carmelitanas de Colombia). Bogotá.

--------. 1990. "Historia de la orden carmelitana en Colombia" (mecanografiado). Bogotá.

Rodriguez, Manuel. 195 “Misioneros españoles en el mundo". El siglo de las misiones. Año XLII (452). Abril.

Rodríguez, José Vicente. 1995 Los trabajos y los días de un misionero enamorado. Juan Vicente Zengotita Bengoa. Biblioteca de autores cristianos. Madrid.

Santidrián, Pedro. 1995 Diccionario breve de pensadores cristianos. Editorial Verbo Divino. Estela.

Santos, Ángel. 1978، “Las misiones católicas". En A. Flichey V. Martín (dirs.). Historia de la Iglesia. De los orígenes a nuestros días. Vol. XIX. Edicep. Val encia.

Severino de Santa Teresa. 1957. Historia documentada de la Iglesia en Urabá y el Darién. Desde el descubrimiento hasta nuestros días. 14921957. Vol úmenes 39-43 Bi blioteca Presidencia dela República. Bogotá.

SотомAYoR, Hugo. 1998. “El diagnóstico de las enfermedades más frecuentes en Colombia". En Mauricio Pérez (ed). El arte de curar. Un viaje a través de la enfermedad en Colombia, 18981998 Afidro. Bogotá.

Strauss, Anselm et al. 1999. "El trabajo que realizan los pacientes hospitalizados". En Carmen de La Cuesta (comp.). Salud y enfermedad. Lecturas básicas en sociología de la medicina. Editorial Universidad de Antioquia. Medellín.

UnZUETA, Antonio, O.C.D. 2001 No niegues lo que eres. Biografía documental del P. Atanasio del Sgdo. Corazón de Jesús (Aguinagalde Aguirreche), 1870-1936. Ediciones orden de Carmelitas Descalzos. Vitoria. 
Vallejo, Gustavo. 1976. Monseñor José Joaquín Arteaga O.C.D. primer prefecto apostólico de Urabá. Homenaje de la provincia carmelita de Colombia y de la Diócesis de Antioquia en el cincuentenario de

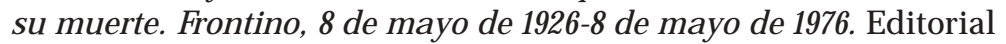
Kelly. Bogotá.

Villegas, Carlos. 1954. “El prefecto de Urabá y las leyendas de Ios pantanos, las fi ebres y las culebras. Informe rendido a la Secretaría de Gobierno en 1930". Álbum de la Carretera al Mar. El Colombiano. Medelín.

Weber, Max. 1978. Sociología de la religión. La Pléyade. Buenos Aires.

Weintraub, Karl J. 1991 “Autobiografía y conciencia histórica”. En Ángel Loureiro (coord.). La autobiografía y sus problemas teóricos. Suplementos Anthropos. 29.

ZINK, MICHEL. 1988. “L'angoisse du héros et la douleur du saint. Souffrance endurée, souffrance contemplée dans la littérature hagiographique et romanesque (XIIe-XIIIe siècles)". La souffrance au moyen âge (France, XIIe-XVe s.). Editions de L'Université de Varsovie. Varsovie.

\section{ARCHIVOS Y SIGLAS}

Archivo General de la orden Carmelita Descalza, Roma. AG.

Archivo de la provincia de San Joaquín de Navarra, Vitoria-Gastéiz. APSJN.

Archivo de la revista mi sionera La Obra Máxima, San Sebastián. AOM.

Archivo histórico de la provincia del Sagrado Corazón de Jesús, Carmelitas Misioneras, Medellín. AHCPM.

\section{Prensa}

El Correo Liberal. Medellín. 1926.

El Correo de Colombia. Medellín. 1926.

La Defensa. Medellín. 1926. 